\title{
Hermaphroditism in fish: incidence, distribution and associations with abiotic environmental factors
}

\author{
Susanna Pla (id) Francesc Maynou (iD) - Francesc Piferrer $(\mathbb{D}$
}

Received: 22 December 2020/Accepted: 22 August 2021/Published online: 5 October 2021

(C) The Author(s) 2021

\begin{abstract}
The distribution of hermaphroditism in fishes has traditionally been mainly explained by its dependence on biotic factors. However, correlates with major abiotic factors have not been investigated on a quantitative basis and at a global scale. Here, we determined the incidence of hermaphroditism in fish at the family and species level, tested the hypothesis that evolutionary relationships account for the poor presence of hermaphroditism in freshwater species, and tested the association of sexual systems with latitude, habitat type and depth. Functional hermaphroditism is reported in 8 orders, 34 families and 370 species of fishes, all teleosts. Sequential hermaphroditism predominates over simultaneous hermaphroditism at a ratio $\sim 5: 1$ and protogyny (female-to-male sex change) predominates $\sim 6: 1$ over protandry (maleto-female). We found 12 hermaphroditic species that can live in freshwater. However, seven of these species are from four primarily marine families while there are only five species from two mostly freshwater families. Protogynous and bi-directional sex changers have a tighter association with reef-associated tropical
\end{abstract}

Supplementary Information The online version contains supplementary material available at https://doi.org/10.1007/ s11160-021-09681-9.

S. Pla $\cdot$ F. Maynou $\cdot$ F. Piferrer $(\bowtie)$

Institute of Marine Sciences, Spanish National Research

Council (CSIC), Passeig Marítim, 37-49,

08003 Barcelona, Spain

e-mail: piferrer@icm.csic.es and subtropical habitats when compared to protandrous species, which tend to be more plastic in terms of distribution requirements. Finally, simultaneous hermaphrodite species live both in the deep sea and shallow waters in similar proportions. This study can be the basis for further research in specific groups for different purposes, including ecological and evolutionary issues as well as conservation and management of exploited species. Understanding the environmental correlates can help to forecast changes in the distribution or phenology of hermaphrodites in a global change scenario.

Keywords Abiotic factors - Environmental correlates $\cdot$ Fishes $\cdot$ Hermaphroditism $\cdot$ Sexual systems · Social system - Williams' paradox

\section{Introduction}

Hermaphroditism, defined as the presence of the male and female function (i.e., sperm and egg production, respectively) in the same individual, either sequentially or simultaneously, is present in the major taxonomic divisions of plants and is common in several Metazoans (Lewis 1942; Leonard 2013). Most invertebrate hermaphrodites are simultaneous and a rough estimate puts the number of hermaphrodite species $\sim 65,000$, or about 5-6\% of animal species, a 
figure that increases to $\sim 30 \%$ if insects are excluded (Jarne and Auld 2006).

The best model to explain when sequential hermaphroditism is favored is the size-advantage model, which predicts that sex change will occur when the reproductive success of one sex increases more rapidly with size (or age) than the reproductive success of the opposite sex (Ghiselin 1969; Warner 1975; Charnov 1982). On the other hand, the bestknown and supported theoretical framework to explain simultaneous hermaphroditism is the low-density model, which suggests that this sexual system is associated with the low probability of finding a partner (Tomlinson 1966; Ghiselin 1969; Charnov 1979; Charnov 1982).

Regarding the benefits of hermaphroditism, it has been accepted that sexual systems should be very sensitive to ecological parameters such as mate availability and reproductive assurance (Jarne and Auld 2006), mate search-efficiency (Eppley and Jesson 2008) and low encounter probability (Leonard 2010). However, the above models do not explain well the distribution of sexual systems in metazoans (Williams 1975). Instead, phylogeny reflects the large-scale distribution of sexual systems better than ecology in plants and metazoans (Leonard 2013 2018). The difference between theory predictions and actual distribution is known as "Williams' paradox" (Leonard 19902013 2018).

Fish are the only vertebrate group where hermaphroditism is present, with two main types. The first main type is sequential hermaphroditism, where individuals can: a) first mature as females, change sex and function as males for the rest of their lives (protogynous species), b) first mature as males, change sex and function as females for the rest of their lives (protandrous species), or c) can revert to the previous sex after change in low density situations (bi-directional sequential hermaphroditism; Sunobe and Nakazono 1993; Munday et al. 2010; Manabe et al. 2013). The second main type is simultaneous hermaphroditism, where both male and female gametes are produced by the same individual, either at the same time or within a very short period of time (Atz 1964; Yamamoto 1969).

Over the years, several studies have attempted to determine the incidence of hermaphroditism in fish. It was estimated to occur in $2 \%$ of 25,000 fish species (Pauly 2004a). Later, it was concluded to be distributed in 20 families in 9 orders (Mank et al. 2006). A plot has been presented displaying about half of the fish species (the ones available in The Tree of Sex) as hermaphroditic (Bachtrog et al. 2014). Discrepancies among estimations may be due to the fact that the diagnosis of hermaphroditism is not straightforward (Sadovy and Shapiro 1987). Criteria for diagnosing functional hermaphroditism in fish should be based on a detailed histological analysis of the gonads in various stages of sexual transition, simultaneous occurrence of mature gonadal tissues and observations of functional sex change (Sadovy and Shapiro 1987; Sadovy and Domeier 2005; Sadovy de Mitcheson and Liu 2008). Following these criteria, and after an extensive review of the literature, functional hermaphroditism was confirmed in 7 orders, 27 families (6\% of all fish families) and 94 genera, but without estimation of actual number of species for each type of hermaphroditism (Sadovy de Mitcheson and Liu 2008). More recent studies have investigated the incidence of hermaphroditism in specific groups, e.g., gobies (Cole 2010; Manabe et al. 2013; Sunobe et al. 2017), serranids (Erisman and Hastings 2011), polynemids (Shihab et al. 2017; Butler et al. 2018) and sparids (Pla et al. 2020) to name some examples, but a global picture, based on current phylogenetic relationships, and with number of species for each major type of hermaphroditism taking into account only confirmed cases is missing. These last points, i.e., based on currently accepted phylogeny and only on confirmed species are very important. In this regard, recently Kuwamura et al. (2020) presented an annotated list of hermaphroditism in fish, with 485 species, but in several of these species functional hermaphroditism had not been confirmed. Further, the phylogenetic relationships were based on the classification of Nelson et al. (2016), which nowadays is considered outdated in many aspects. Nevertheless, the work of Kuwamura et al. (2020) is relevant because the analysis of the different forms of hermaphroditism with the mating system provides support for the size-advantage model. Based on the above, the first aim of this study was to provide an update of the different types of sexual systems in fish, focusing on the incidence of hermaphroditism at the species level, based on currently accepted phylogenetic relationships, and considering only confirmed species. 
As explained above, at a small-scale, in fish the most important ecological drivers of hermaphroditism are social structure and mating system (Warner 1988; Munday et al. 2006; Godwin 2009). A comprehensive study in various fish lineages confirmed that social and mating systems, not evolutionary history, were the main drivers (Erisman et al. 2013; Kuwamura et al. 2020). However, one of the conclusions of the Sadovy de Mitcheson and Liu (2008) review was the need to also pay attention to the contribution of abiotic factors to better understand the distribution of hermaphroditism in fish because these, when compared to the influence of biotic factors, have received less attention (Sadovy de Mitcheson and Liu 2008). In fact, several studies show that fine-scale variation in the physical environment can influence community dynamics (Menke and Holway 2006) and this could affect reproduction. In the case of hermaphrodites, increased temperature due to global warming could affect the synthesis of sex steroids and influence the temporal dynamics of sex change (Pankhurst and Munday 2011). In this regard, in aquatic ecology four important abiotic factors are salinity, latitude (temperature), habitat type and depth (Margalef 1998).

Functional hermaphroditism has traditionally been considered either absent or very rare in freshwater habitats (Sadovy de Mitcheson and Liu 2008; Pavlov et al. 2009; Wootton and Smith 2014; Kuwamura et al. 2020). The number of hermaphroditic species in freshwater was calculated to represent only $\sim 3 \%$ of the total number of hermaphroditic species, in clear contrast with the fact that freshwater fish species account for about half the number of all fish species (Kuwamura et al. 2020). The underlying cause is unknown but explanations for this phenomenon have relied on morphological aspects such as egg size. Thus, compared to marine fish, freshwater fish tend to spawn fewer and larger demersal eggs and larvae (Freedman and Noakes 2002; Pavlov et al. 2009). It has been argued that anatomical differences in the reproductive ducts may accentuate the physical differences in male and female anatomy, forming a sort of barrier for the development of hermaphroditism (Warner 1978; Sadovy de Mitcheson and Liu 2008). Also, parental care, common in freshwater fish, may reduce differences in reproductive success among sexes, as proposed by the size-advantage model, thus not favoring hermaphroditism (Sadovy de Mitcheson and Liu 2008). However, to the best of our knowledge, these hypotheses have not formally been tested, perhaps because more data needs to be collected. In any case, the low preponderance of hermaphroditism in freshwater fishes remains to be explained since it constitutes a gap in knowledge. Recently, the origin of vertebrates has been placed in shallow intertidal and subtidal environments (Sallan et al. 2018). However, trait reconstructions suggest that all extant marine Actinopterygians (ray-finned) fishes, the most speciesrich clade of marine vertebrates, containing $96 \%$ of fish species with roughly similar number of marine and freshwater species, were derived from a freshwater ancestor (Vega and Wiens 2012). Both marine and freshwater habitats are dominated by two clades, the Ostariophysi and the Percomorpha, although, interestingly, the most species-rich families of freshwater fishes (e.g., Cyprinidae, Cichlidae) do not contain hermaphrodite species (Sadovy de Mitcheson and Liu 2008). Knowledge on the association of the different sexual systems according to water salinity can provide opportunities to test hypotheses of possible adaptive significance of variations in sexual system (Sadovy de Mitcheson and Liu 2008). However, to the best of our knowledge, the distribution of the different sexual systems at species level in different water salinities has never been addressed on a numerical basis and on an evolutionary perspective. Thus, the second aim of this study was to test the hypothesis that evolutionary relationships account for the low presence of hermaphroditism in freshwater.

Latitude and temperature are closely linked. Temperature influences many aspects of aquatic ectotherms like fish such as survival, distribution, growth and reproductive output (Conover 1992; Heibo et al. 2005; Ruttenberg et al. 2005; Trip et al. 2008). It has been speculated that sex change at high latitudes is physiologically limited (Trip et al. 2011) because of the high associated energetic costs (Sadovy de Mitcheson and Liu 2008), despite that some protogynous species are found at high latitudes, e.g., Odax pullus (Trip et al. 2011) and Labrus bergylta, (Muncaster et al. 2010). The study of the distribution of the different sexual systems between each latitude region can help in future comparative analyses of ecological and geographical traits (Sadovy de Mitcheson and Liu 2008). In this regard, Pauly (2004b) showed a preponderance of hermaphrodites close to tropical areas. Thus, sequential hermaphroditism, especially protogyny, is associated with shallow tropical marine 
reef habitats (Warner 1984; Sadovy de Mitcheson and Liu 2008). This has been explained by ecological stability for the abundance of food (Barlow 1975) and predictable mating opportunities that these habitats offer, but whether this richness is a consequence of the higher abundance of species at low latitudes is not known. Also, and to the best of our knowledge, a quantitative assessment of the distribution of the different forms of hermaphroditism with different types of habitats has never been made. On the other hand, simultaneous hermaphroditism has been associated with the deep-sea (Ghiselin 1969; Baldwin and Johnson 1996; Davis and Fielitz 2010) in accordance with the low-density model (Ghiselin 1969). The classical example concerns several families of Aulopiformes (Davis and Fielitz 2010). However, simultaneous hermaphrodites are also present in shallow waters mostly represented by members of the family Serranidae but the relative distribution of simultaneous hermaphrodite species has not been addressed in a quantitative manner either. Thus, based on the above, the third aim of this study was to quantitatively test the association of the different sexual systems according to latitude, habitat and depth, taking into account phylogenetic relationships.

\section{Materials and methods}

\section{Creation of an ad hoc comprehensive database}

We collected information on the sexual system of fishes from the primary literature, taking also into account previous general reviews (Sadovy de Mitcheson and Liu 2008), reviews on specific groups or families, e.g., Sparidae (Pla et al. 2020); Serranidae (Erisman and Hastings 2011). In total we searched 379 papers (references in the Supplementary information). We also obtained information on the following environmental variables, collected from FishBase (www.fishbase.com; Froese and Pauly 2018): salinity, latitude, habitat, and depth (see below for further details). Importantly, in this study we only consider as being functional hermaphrodites those species where evidence has been based on the criteria of Sadovy and Shapiro (1987) as in Sadovy de Mitcheson and Liu (2008), but not in those cases where evidence has been inferred and is not direct, or when functional hermaphroditism has not been fully confirmed. For taxonomic classification level higher than genus and species, as well as the most updated counts of valid species, we used Eschmeyer's Catalog of Fishes database (Fricke et al. 2019): http://researcharchive.calacademy. org/research/ichthyology/catalog/fishcatmain.asp. For evolutionary relationships, we used a comprehensive and updated phylogenetic tree of Actinopterygian fishes (Rabosky et al. 2018). The information provided here represents an expanded, curated and validated version of the dataset of Pla (2019) with only cases that could be confirmed.

Statistical analysis

In this study, the sexual system was always the dependent variable. Sexual system was treated as nominal categorical variable that, for a given species, could take one of the following values: gonochorism, protogyny, protandry, bi-directional sex change or simultaneous hermaphroditism. Because of the handful number of androdioecious species (species consisting of males and simultaneous hermaphrodites) in fish (Costa 2016; Petersen and Fischer 1986; Petersen 1990), this sexual system was not contemplated here. On the other hand, the independent variables or abiotic environmental factors considered were: salinity, latitude, habitat, and depth.

Regarding salinity, the presence or absence of a given species in each one of the three major types of water salinities (freshwater, brackish water and saltwater) in FishBase was coded as a binary variable with the values of 1 or 0 , respectively. This allowed to account for the possibility that one species could be present in more than one type of water salinity. We then tested the association of the different sexual systems with the different water salinities types employing a multinomial generalized linear model (GLM) using the library nnet in R (Ripley et al. 2016).

Latitude was treated as a nominal categorical variable with the following categories: tropical, subtropical, temperate, and boreal. Each species was assigned to only one of the latitude categories, the most frequent one in case of being present in more than one. We tested the association of the different types of sexual systems with latitude categories with a multinomial GLM.

Habitat was also treated as a nominal categorical variable with the following possible categories: bathydemersal, bathypelagic, benthopelagic, demersal and reef-associated. The pelagic habitat was not 
considered because no hermaphrodites were present in this habitat. Each species was assigned to only one of the habitat categories, the most frequent one in case of being present in more than one. We tested the association of different types of hermaphroditism with these different marine habitats and to do so we used a multinomial GLM, as described above for salinity.

As for depth, we took into account depth data (all in meters) provided by FishBase: depth shallow, the shallowest depth at which a given species is found; depth common shallow, the mean upper depth at which a given species is commonly found; depth common deep, the mean bottom depth at which a given species is commonly found; and depth deep, the maximum depth reported for a given species. We tested the distribution of simultaneous hermaphroditism as a function of depth. To that end, a multinomial GLM on $\log$ depth deep was used. All data for the hermaphroditic species considered in this study can be found in the online Supplementary information. Importantly, because of the breakdown of the different types of hermaphroditism (numbers of species in the range of $\sim 20$ to $\sim 245$ depending on type; see the "Summary tables" in the database of the Supplementary information) combined with the low number of records for some of the abiotic factors, it was not possible, despite our attempts, to properly correct for phylogenetic signal, understood as the tendency for related species to resemble each other more for a given trait, in our case sexual system, than they resemble species drawn at random from the tree (Orzack and Sober 2001; Blomberg and Garland 2002). We thus were aware that this is a limitation that could potentially affect the results of the second and third objectives of this study, but not the first one, and therefore have taken every precaution we could in the interpretation of the results.

To check the sensitivity of the GLM results to the fact that certain categories are much more abundant than others (e.g., fishes are particularly abundant at tropical latitudes, in coral reefs and demersal habitats), we randomized the original data set by keeping the number of species per environmental factor category fixed and resampling the sexual system (50,000 times, without replacement). A Chi-square statistic was recalculated at each iteration to examine whether the contingency table observed could be within any of the randomly generated contingency tables by the resampling algorithm.

\section{Results}

Incidence and distribution of the different forms of hermaphroditism in fishes

A summary of the incidence of the different types of hermaphroditism in fish and their classification in orders and families is shown in Table 1. A detailed list of all the confirmed functional hermaphrodite fish species considered in this study and their supporting primary literature can be found in the Supplementary information.

Functional hermaphroditism has been confirmed in eight of the extant 54 orders of fish according to Fricke et al. (2019). These orders are: Anguilliformes, Aulopiformes, Centrarchiformes, Gobiiformes, Perciformes, Scorpaeniformes, Stomiiformes and Synbrachiformes (Table 1).

We collected information on the sexual system of species belonging to 316 families, i.e., $\sim 60 \%$ of the 514 families of Actinopterygian fishes according to Fricke et al. (2019). We found functional hermaphroditism in 34 families, all of them within the teleosts, and a total of 370 hermaphrodite species. The five families with the higher number of hermaphrodite species were Serranidae (91 spp.; Note: according to the above classification this includes the Epinephelidae), Labridae (63 spp.), Gobiidae (41 spp.), Sparidae (40 spp.) and Scaridae (23 spp.). The number of hermaphrodite species in the remaining 29 families ranged from 1 to 16 (Table 1).

Sequential hermaphroditism clearly predominated over simultaneous hermaphroditism (305 vs. 65 spp.), i.e., at a ratio of $\sim 5: 1$. Thus, $82.4 \%$ of hermaphrodite fish are sequential hermaphrodites. Within sequential hermaphroditism, protogyny clearly predominates (244 species; $80 \%$ of 305 ) followed by protandry (39 species; $12.8 \%$ of 305 ; ratio protogyny:protandry $\sim 6: 1)$ and bi-directional sequential hermaphroditism (22 species; $7.2 \%$ of 305 ; Fig. 1).

Distribution of hermaphroditism according to water salinity

We compiled information on salinity preference for the 370 hermaphroditic species (details in the Supplementary information). We did not include Squalius alburnoides, Henicorhynchus lobatus and Crenicara punctulatum because lack of enough evidence to consider that hermaphroditism is their usual form of 
Table 1 List of the orders and families where functional hermaphroditism has been confirmed in fish, indicating the number of species in each type of hermaphroditism

\begin{tabular}{|c|c|c|c|c|c|c|c|c|}
\hline \multirow[t]{2}{*}{ Order $^{1}$} & \multirow[t]{2}{*}{ Family* } & \multirow{2}{*}{$\begin{array}{l}\text { No. of } \\
\text { species }^{1}\end{array}$} & \multicolumn{4}{|c|}{ Hermaphroditism } & \multirow{2}{*}{$\begin{array}{l}\text { Total Hermaphr. } \\
(\mathrm{PG}+\mathrm{PA}+ \\
\mathrm{BD}+\mathrm{SH})\end{array}$} & \multirow{2}{*}{$\begin{array}{l}\text { Total Hermaphr. / } \\
\text { no. spp. per } \\
\text { family }(\%)\end{array}$} \\
\hline & & & PG & PA & $\mathrm{BD}$ & $\mathrm{SH}$ & & \\
\hline Anguilliformes & Muraenidae & 213 & - & - & - & 2 & 2 & 0.94 \\
\hline \multirow[t]{11}{*}{ Aulopiformes } & Alepisauridae & 2 & - & - & - & 2 & 2 & 100.00 \\
\hline & Anotopteridae & 3 & - & - & - & 1 & 1 & 33.33 \\
\hline & Bathysauridae & 2 & - & - & - & 2 & 2 & 100.00 \\
\hline & Chlorophthalmidae & 21 & - & - & - & 5 & 5 & 23.81 \\
\hline & Evermannellidae & 8 & - & - & - & 2 & 2 & 25.00 \\
\hline & Giganturidae & 2 & - & - & - & 2 & 2 & 100.00 \\
\hline & Ipnopidae & 33 & - & - & - & 5 & 5 & 15.15 \\
\hline & Notosudidae & 17 & - & - & - & 3 & 3 & 17.65 \\
\hline & Omosudidae & 1 & - & - & - & 1 & 1 & 100.00 \\
\hline & Paralepididae & 71 & - & - & - & 8 & 8 & 11.26 \\
\hline & Scopelarchidae & 18 & - & - & - & 4 & 4 & 22.22 \\
\hline Centrarchiformes & Cirrhitidae & 35 & 6 & - & - & - & 6 & 17.14 \\
\hline Gobiiformes & Gobiidae & 1,907 & 18 & - & 21 & 2 & 41 & 2.15 \\
\hline \multirow[t]{16}{*}{ Perciformes } & Centropomidae & 12 & - & 1 & - & - & 1 & 8.33 \\
\hline & Eleginopsidae & 1 & - & 1 & - & - & 1 & 100.00 \\
\hline & Labridae & 556 & 63 & - & - & - & 63 & 11.33 \\
\hline & Latidae & 14 & - & 1 & - & - & 1 & 7.14 \\
\hline & Lethrinidae & 44 & 10 & - & - & - & 10 & 22.73 \\
\hline & Nemipteridae & 73 & 3 & - & - & - & 3 & 4.11 \\
\hline & Odacidae & 12 & 1 & - & - & - & 1 & 8.33 \\
\hline & Pinguipedidae & 98 & 1 & - & - & - & 1 & 1.02 \\
\hline & Polynemidae & 42 & - & 3 & - & - & 3 & 7.14 \\
\hline & Pomacanthidae & 90 & 16 & - & - & - & 16 & 17.78 \\
\hline & Pomacentridae & 420 & 5 & 10 & - & - & 15 & 3.57 \\
\hline & Pseudochromidae & 154 & 4 & - & 1 & - & 5 & 3.25 \\
\hline & Scaridae & 100 & 23 & - & - & - & 23 & 23.00 \\
\hline & Serranidae * & 546 & 65 & - & - & 26 & 91 & 16.66 \\
\hline & Sparidae & 166 & 22 & 18 & - & - & 40 & 24.09 \\
\hline & Trichonotidae & 10 & 1 & - & - & - & 1 & 10.00 \\
\hline \multirow[t]{2}{*}{ Scorpaeniformes } & Scorpaenidae & 454 & 2 & - & - & - & 2 & 0.44 \\
\hline & Platycephalidae & 84 & - & 4 & - & - & 4 & 4.76 \\
\hline Stomiiformes & Gonostomatidae & 33 & - & 1 & - & - & 1 & 3.03 \\
\hline Synbranchiformes & Synbranchidae & 26 & 4 & - & - & - & 4 & 15.38 \\
\hline \multirow[t]{2}{*}{ Subtotal } & & 5,268 & 244 & 39 & 22 & 65 & 370 & 7.02 \\
\hline & Rest of species & 28,518 & - & - & - & - & - & \\
\hline Total & & 33,786 & 244 & 39 & 22 & 65 & 370 & 1.09 \\
\hline
\end{tabular}

$P G$ Protogyny; $P A$ Protandry; $B D$ Bi-Directional; $S H$ Simultaneous hermaphroditism.

${ }^{1}$ Taxonomic classification and number of species counts from Fricke et al. (2019).

* In this classification, Serranidae includes the Epinephelidae. Androdioceous species (e.g., members of the F. Rivulidae) not included 


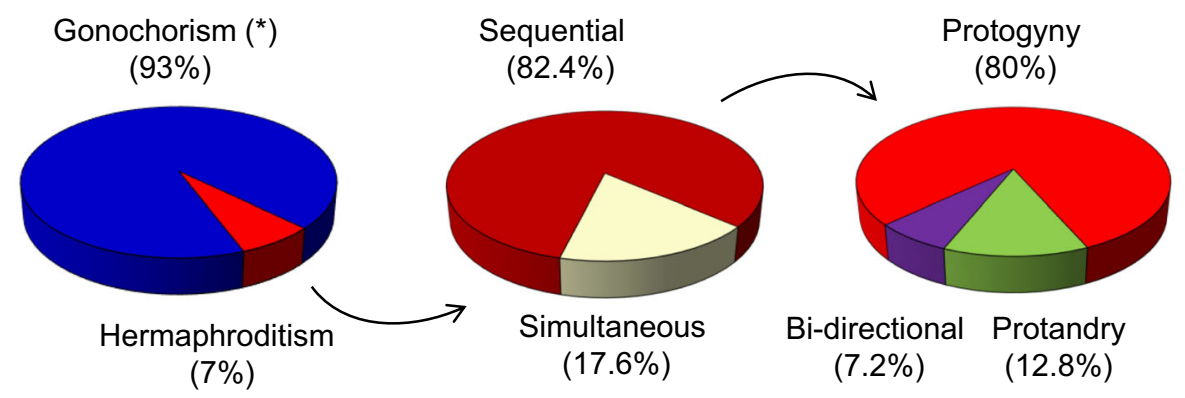

Fig. 1 Graphical representation of the relative abundance of the major sexual systems among teleost fishes. Sample sizes: Gonochorism, $\mathrm{n}=5,268(*)$ please note, this takes into account only the gonochoristic species from families that also contain hermaphrodite species, not the total number of extant species that are gonochores; Hermaphroditism, $n=370$; Sequential

reproduction in the wild, despite some studies finding evidence of intersex gonads (Carruth 2000; Matos et al. 2010; Collares-Pereira et al. 2013).

Of the 244 protogynous species, 216 species $(88.5 \%)$ were exclusively found in saltwater, 23 species $(9.4 \%)$ both in saltwater and brackish water, none exclusively in brackish water, 1 species (0.4\%), Lophogobius cyprinoides, in saltwater, brackish water and freshwater, 3 species (1.2\%), Synbranchus marmoratus, Ophisternon bengalense and Monopterus albus, both in brackish water and freshwater, and 1 species $(0.4 \%)$, Monopterus boueti, exclusively in freshwater. Regarding the 39 protandrous species, 20 species $(74.4 \%)$ were exclusively found in saltwater, 12 species $(30.7 \%)$ both in saltwater and brackish water, none exclusively in brackish water, 7 species (18\%) in saltwater, brackish water and freshwater, none both in brackish water and freshwater, and none exclusively in freshwater. Regarding the 22 bi-directional species, 21 species $(95.5 \%)$ were exclusively found in saltwater, 1 species $(4.5 \%)$, Priolepis cincta, both in saltwater and brackish water, and

Table 2 Distribution of the different forms of hermaphroditism in fish (PG, protogyny; PA, protandry; BD, bi-directional; $\mathrm{SH}$, simultaneous hermaphroditism) according to water salinity. Androdioecy not considered. Notice that the number of hermaphroditism, $\mathrm{n}=305$; Simultaneous hermaphroditism, $n=65$; Protogyny, $n=244$; Protandry, $n=39$; Bi-directional hermaphroditism, $n=22$. Parthenogenesis (i.e., unisexuality, $\mathrm{n}=2)$ and androdioecy $(\mathrm{n}=3)$ were not included due to the very low number of species and difficulty of visualization

none in any of the remaining combinations. Finally, of the 65 simultaneous hermaphrodite species, 62 species (95.4\%) were exclusively found in saltwater, 3 species (4.6\%), Chlorophthalmus agassizi, Diplectrum radiale and Serranus psittacinus, both in saltwater and brackish water, and none in any of the remaining combinations (Fig. 2a). Recall we are not considering here the androdioecious species (e.g., from the genus Kryptolebias). Thus, we found a total of twelve species of hermaphrodites present in freshwater (Supplementary information) of which seven species were from four mostly seawater families (Gobiidae, Centropomidae, Polynemidae and Sparidae) that can be found also in brackish water and fresh water, and five species from two families that mainly live in freshwater: the catadromous protandrous Lates calcarifer (Latidae), and the protogynous Monopterus boueti, M. albus, Ophisternon bengalense and Synbranchus marmoratus (Synbranchidae).

Since a given species could be present in more than one type of water salinity, Table 2 shows the number of species of each type of hermaphroditism according

\begin{tabular}{|c|c|c|c|c|c|c|c|c|}
\hline & PG & $(\%)$ & PA & $(\%)$ & $\mathrm{BD}$ & $(\%)$ & $\mathrm{SH}$ & $(\%)$ \\
\hline Saltwater & 240 & 88.2 & 39 & 60.0 & 22 & 95.7 & 65 & 95.6 \\
\hline Brackish water & 27 & 9.9 & 19 & 29.2 & 1 & 4.3 & 3 & 4.4 \\
\hline Freshwater & 5 & 1.8 & 7 & 10.8 & 0 & 0 & 0 & 0 \\
\hline Totals & 272 & 100 & 65 & 100 & 23 & 100 & 68 & 100 \\
\hline
\end{tabular}


(a)

\section{Protogynous}

Protandrous

\section{Bi-directional}

\section{Simultaneous}
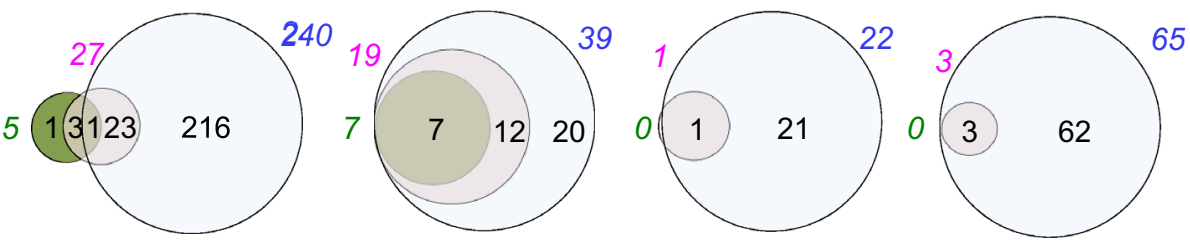

Freshwater

Brackish water

Saltwater

(b)

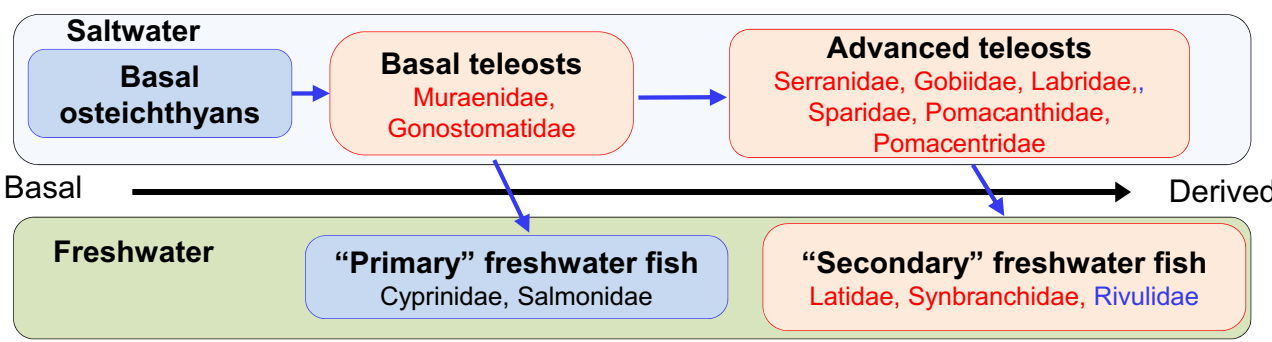

(c)

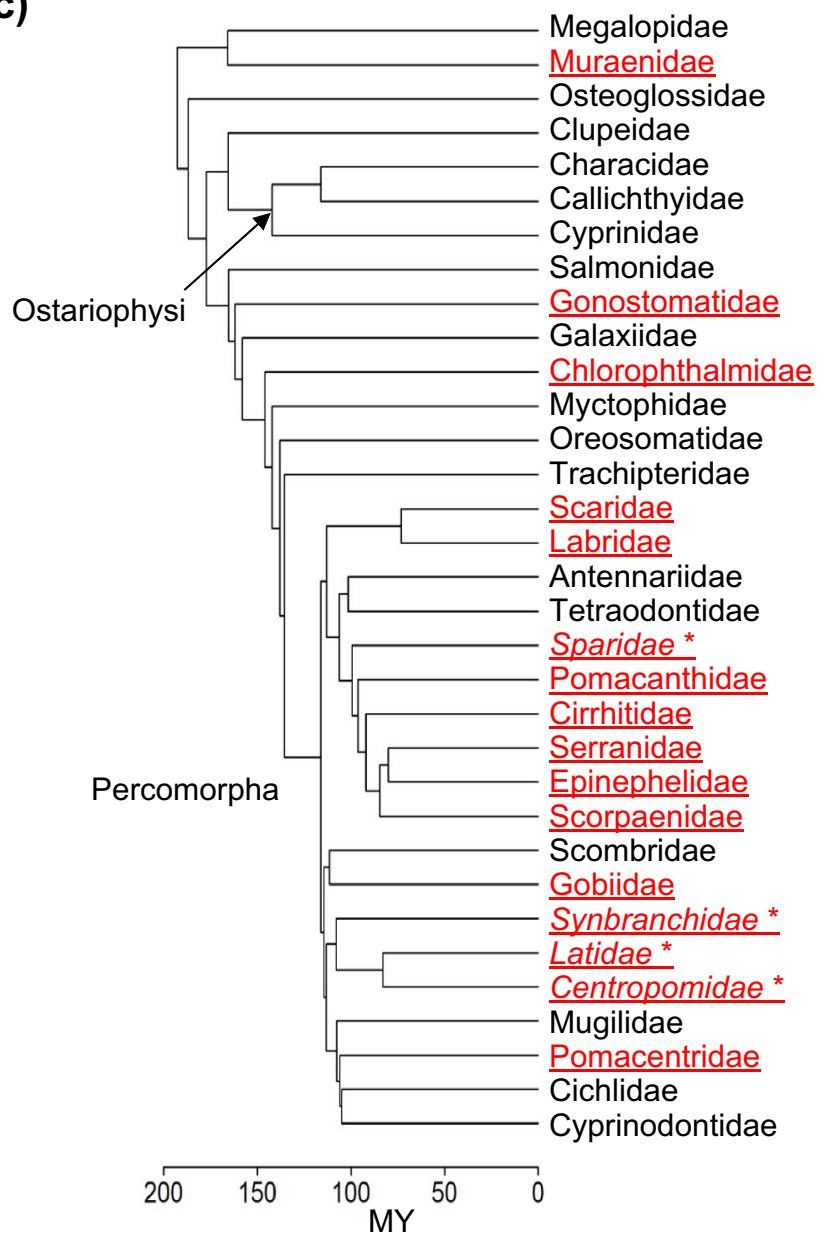

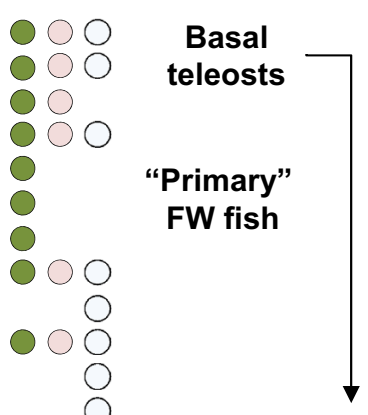

Advanced teleosts

0

0

100

$0 \bigcirc 0$

0

- 0

00

00

00

00

00

000

00

00

"Secondary"

FW fish 
4Fig. 2 Distribution of the different forms of hermaphroditism according to water salinity. a Numerical distribution of the different types of hermaphroditism in freshwater, brackish water and saltwater. Numbers in italics outside the circles represent the total number of species of a given sexual system found in freshwater (left, in green), brackish water (top, in purple) and saltwater (right, in blue). Numbers inside the colored circles represent the actual number of species in each type of salinity. b The distribution of hermaphroditism in the context of fish evolution, indicating two episodes of freshwater invasion (modified from Witten and Huysseune 2009). Family names in black indicate gonochorism, in red hermaphroditism and in blue androdioecy. c Incidence of hermaphroditism in Actinopterygian phylogeny based on the Rabosky et al. (2018) tree. Circle color codes indicate presence of the family in the three major salinity types: green $=$ freshwater; pink = brackish water; light blue = saltwater. Orders (and family) names indicate gonochorism (black) and, marked in red and underlined, are the families containing hermaphrodites. Among these families, marked in italics and an asterisk are those that, in addition, contain hermaphrodite species in freshwater. Note that family Polynemidae, which contains hermaphrodites in freshwater is not represented because it is not included in the Rabosky et al. (2018) tree

to water salinity. The ratio of species occurrence in saltwater, brackish water and fresh water was 48:5.4:1 for protogynous species and $\sim 6: 3: 1$ for protandrous species. In accordance, the results of the multinomial GLM showed hermaphrodites were underrepresented in freshwater (significantly so for protogynous and simultaneous hermaphrodites; $P<0.001$ ). Conversely, protandric hermaphrodites were relatively more frequent in brackish waters when compared to the other forms of hermaphroditism $(P<0.001)$. Saltwater showed proportionally higher representation of bidirectional, protandric and simultaneous hermaphrodites $(P<0.001$; Table 3$)$.

From an evolutionary point of view, basal osteichthyans do not contain hermaphroditic species. Hermaphroditism is first found in basal teleosts of the families Muraenidae (two simultaneous hermaphrodite species) and Gonostomatidae (one protandrous species), all marine (Fig. 2b). Most hermaphrodite species belong to families of derived teleosts, including the twelve hermaphrodite species found in freshwater (Fig. 2c).
Table 3 GLM results of the different forms of hermaphroditism in fish (PG, protogyny; PA, protandry; BD, bi-directional; $\mathrm{SH}$, simultaneous hermaphroditism) according to salinity

\begin{tabular}{llllr}
\hline & Intercept & Freshwater & Brackish water & Saltwater \\
\hline \multicolumn{2}{l}{ Coefficients } \\
BD & -22.2274 & -0.4264 & -0.7864 & 16.9735 \\
PA & -22.2926 & -0.3151 & 1.7474 & 16.9899 \\
PG $\quad-4.1858$ & -2.7322 & 0.1126 & 1.2520 \\
SH & -21.6861 & -42.6399 & -0.7705 & 17.5149 \\
P-values & & & \\
BD & 0.0000 & 0.7022 & 0.4429 & 0.0000 \\
PA & 0.0000 & 0.5126 & 0.0000 & 0.0000 \\
PG & 0.0000 & 0.0007 & 0.5957 & 0.1633 \\
SH & 0.0000 & 0.0000 & 0.1941 & 0.0000 \\
\hline
\end{tabular}

Chi-square statistic $=260.76, P<0.001$

The Chi-square statistic refers to the result of the randomization test

Hermaphroditism and latitude

We obtained data on the most common latitude distribution for all the 370 hermaphroditic species. Eighteen species, all of them simultaneous hermaphrodites, had a circumglobal distribution. Of the 352 remaining species, $225(\sim 64 \%)$ inhabited tropical regions. The number of hermaphrodite species was inversely related with latitude. Protogynous hermaphrodites predominated in all but the boreal regions, where simultaneous hermaphrodites were the most abundant type (Fig. 3a). Analysis of the latitudinal distribution as a function of the sexual system showed significant differences. Thus, GLM (tropical as reference) showed that sequential hermaphrodites, specifically protogynous species, were significantly more frequent in the tropical and subtropical latitudes $(P<0.001)$. Conversely, the latitudinal distribution of simultaneous hermaphrodites was significantly different from that of the rest of hermaphrodites $(P<0.001)$ while protandrous hermaphrodites were underrepresented (Table 4). 
(a)
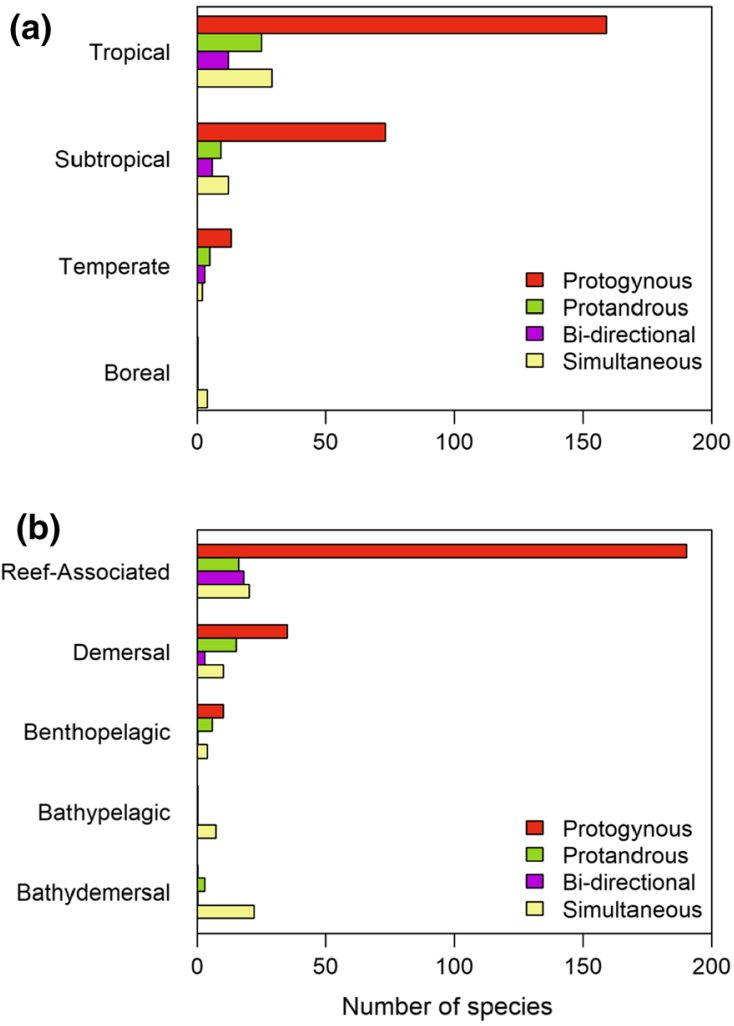

Fig. 3 Distribution of the different forms of hermaphroditism according to the latitude and habitat. a Latitude. Sample sizes: Protogyny, $\mathrm{n}=244$; Protandry. $\mathrm{n}=39$; Bi-directional hermaphroditism, $\mathrm{n}=22$; Simultaneous hermaphroditism, $\mathrm{n}=47$. b Habitat. Sample sizes: Protogyny, $\mathrm{n}=235$; Protandry, $\mathrm{n}=38$; Bi-directional hermaphroditism, $\mathrm{n}=22$; Simultaneous hermaphroditism, $\mathrm{n}=63$
To confirm that higher incidence of hermaphroditism is not due to the high number of species in the tropics, we randomized the original data set by keeping the number of species per latitudinal category fixed and resampling the type of reproduction $(50,000$ times, without replacement). The chi-square statistic was recalculated at each iteration. The expected distribution of the chi square statistic is approximately 0 . As shown in Supplementary Fig. 1, the chi-square statistic estimated from the original data set does not fall within the values of the 50,000 randomized data sets $(\mathrm{P}<0.001)$.

The association of hermaphroditism with different marine habitats

Most hermaphrodites, particularly sequential hermaphrodites, are associated with reefs and, to a much lower degree, with demersal and benthopelagic habitats. Their presence in bathypelagic and bathydemersal habitats is much lower (Fig. 3b). In particular, protogynous hermaphrodites had a high probability to be found in reefs and low probability to be found in the benthopelagic $(P<0.001)$. However, protandry had a similar presence in reefs and demersal $(\sim 40 \%$ each; $\mathrm{n}=16$ and $\mathrm{n}=15$, respectively), with fewer species present in benthopelagic $(16 \%, \mathrm{n}=6)$ and bathypelagic $(3 \%, \mathrm{n}=1)$ habitats (no statistical difference).

Table 4 GLM results of the different forms of hermaphroditism in fish (PG, protogyny; PA, protandry; BD, bi-directional; SH, simultaneous hermaphroditism) according to latitude

\begin{tabular}{lllll}
\hline & Intercept $=$ Tropical & Subtropical & Temperate & Boreal \\
\hline Coefficients & & & & \\
BD & -21.0012 & 1.0548 & -0.0100 & -0.0207 \\
PA & -25.8240 & 0.7004 & -0.3045 & $-65,770$ \\
PG & -41.2009 & 3.6007 & -3.5711 & $-1,083,069$ \\
SH & -27.0041 & 1.1964 & -1.6590 & 6.4617 \\
P-values & & & & \\
BD & 0.000 & 0.2915 & 0.9920 & 0.9835 \\
PA & 0.000 & 0.4837 & 0.7607 & 0.0000 \\
PG & 0.000 & 0.0003 & 0.0004 & 0.0000 \\
SH & 0.000 & 0.2315 & 0.0971 & 0.0000 \\
\hline
\end{tabular}

Chi-square statistic $=160.65, P<0.001$

The Chi-square statistic refers to the result of the randomization test 
Table 5 GLM results of the different forms of hermaphroditism in fish (PG, protogyny; PA, protandry; BD, bi-directional; SH, simultaneous hermaphroditism) according to habitat

\begin{tabular}{|c|c|c|c|c|c|}
\hline & Intercept $=$ Demersal & Bathydemersal & Bathypelagic & Benthopelagic & Reef- associated \\
\hline \multicolumn{6}{|c|}{ Coefficients } \\
\hline $\mathrm{BD}$ & -6.8649 & -11.9682 & -6.7859 & -79.6199 & 2.3716 \\
\hline PA & -5.2556 & -12.3894 & -0.0773 & -0.8467 & 0.5899 \\
\hline PG & -4.3005 & -13.2321 & -9.3719 & -1.2907 & 2.1098 \\
\hline $\mathrm{SH}$ & -5.6611 & 1.6183 & 3.4195 & -0.8459 & 1.2189 \\
\hline \multicolumn{6}{|c|}{ P-values } \\
\hline $\mathrm{BD}$ & 0.0000 & 0.0000 & 0.9156 & 0.0000 & 0.0001 \\
\hline PA & 0.0000 & 0.9713 & 0.9405 & 0.0801 & 0.1020 \\
\hline PG & 0.0000 & 0.9673 & 0.8848 & 0.0003 & 0.0000 \\
\hline $\mathrm{SH}$ & 0.0000 & 0.0011 & 0.0000 & 0.1531 & 0.0017 \\
\hline
\end{tabular}

Chi-square statistic $=755.21, P<0.001$

The Chi-square statistic refers to the result of the randomization test

Bi-directional hermaphrodites were mostly associated with reefs $(86 \%, \mathrm{n}=19)$ and demersal $(14 \%, \mathrm{n}=3)$ habitats, and significantly less abundant in the benthopelagic and bathydemersal. On the other hand, simultaneous hermaphroditism was found to be significantly reef-associated $\quad(\mathrm{n}=20, \quad 32.2 \%$; $P<0.01)$ and the predominant form in bathypelagic ( $\mathrm{n}=22 ; 35.5 \%, \quad \mathrm{P}<0.001)$ and bathydemersal (n $=7 ; 11.3 \% ; P<0.01$ ) habitats (Table 5; Fig. 3b).

The association of hermaphroditism with depth

Of the 65 species with verified simultaneous hermaphroditism, only members of the order Aulopiformes inhabit the deep-sea. In contrast, we found that the maximum depth attained by simultaneous hermaphrodite species from other orders, i.e., Perciformes (26 species of the genus Serranus, Hypoplectrus and Diplectrum), Gobiiformes (two Priolepis sp.) and Anguilliformes (two Gymnothorax sp.), are not found beyond the first $\sim 500 \mathrm{~m}$ (Fig. 4a). GLM results showed that simultaneous hermaphroditism is relatively more frequent with increasing depth $(P<0.001)$. (Table 6). However, binning depth values in ranges of $200 \mathrm{~m}$, showed that 25 hermaphroditic species live within the first $200 \mathrm{~m}$ and 31 hermaphroditic species (i.e., $\sim 50 \%$ of the total) within the first $400 \mathrm{~m}$ of the water column (Fig. 4b). The mean depth values of these species were $74.6 \mathrm{~m}$ for the $0-200 \mathrm{~m}$ range ( $\mathrm{n}=25$ species); $337.6 \mathrm{~m}$ for the 201-400 m range ( $\mathrm{n}=6$ species) and $2,392 \mathrm{~m}$ for $>400 \mathrm{~m}(\mathrm{n}=31$ species Fig. $4 \mathrm{c})$. These results indicate that although there is an increase with depth, the number of simultaneous hermaphrodite species 
(a)

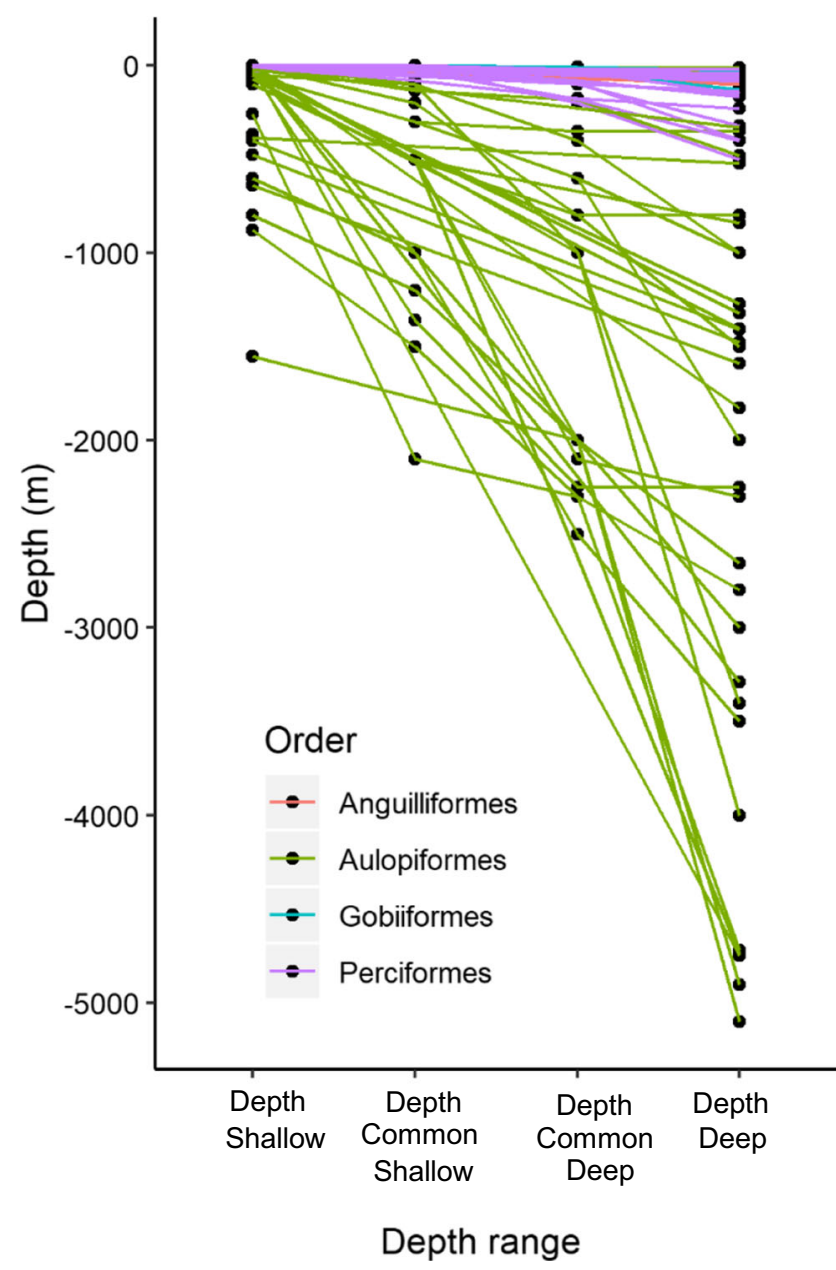

(b)
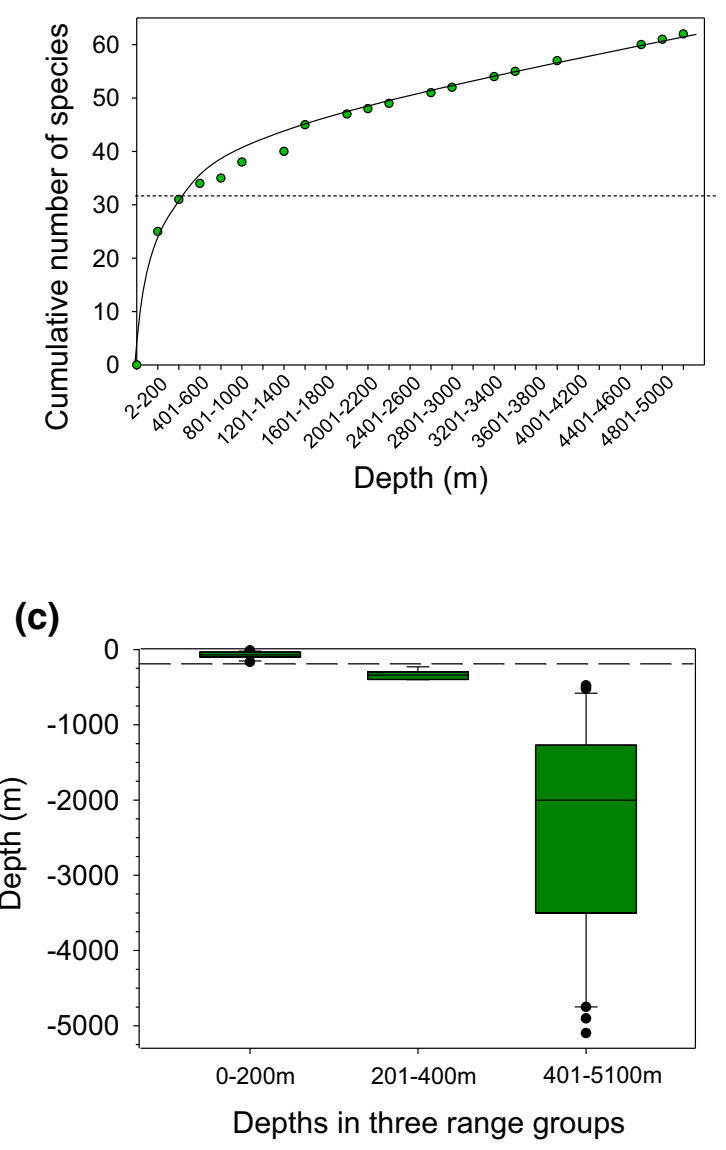

Fig. 4 Distribution of simultaneous hermaphroditism according to depth. a Distribution at four depth points (see Methods for definitions) of species belonging to four different orders. Number of species in each one of the four depths are: Aulopiformes, $\mathrm{n}=29 ; 18 ; 17$ and 29, Perciformes, $\mathrm{n}=25 ; 14$; 14 and 25, Gobiiformes, $\mathrm{n}=2 ; 2 ; 2$ and 2, and Anguilliformes, $\mathrm{n}=2 ; 0 ; 0$ and 2 . $\mathbf{b}$ Cumulative number of species as a function

Table 6 GLM results of the different forms of hermaphroditism in fish (PG, protogyny; PA, protandry; BD, bi-directional; $\mathrm{SH}$, simultaneous hermaphroditism) according to depth

\begin{tabular}{lll}
\hline & Estimate & $P$-value \\
\hline Intercept & -6.905 & 0.0000 \\
$\log ($ DepthDeep $)$ & 0.5219 & 0.0000 \\
\hline
\end{tabular}

whose maximum depth is restricted to shallow waters $(\leq 200 \mathrm{~m})$ is similar to those whose maximum depth is $>400 \mathrm{~m}$. of maximum depth. (c) Distribution of simultaneous hermaphrodites in three depth ranges: $0-200 \mathrm{~m}(\mathrm{n}=24) ; 201-400 \mathrm{~m}$ $(n=6) ; 401-5100 \mathrm{~m}(\mathrm{n}=28)$. The edges of the box closed and farthest from zero indicate the $25^{\text {th }}$ and $75^{\text {th }}$ percentiles, respectively. Within boxes, the thin line indicates the median. Whiskers above and below the box indicate the 90th and 10th percentiles respective

\section{Discussion}

Incidence and distribution of the different forms of hermaphroditism in fishes

Of the eight orders with hermaphroditism present, six (Anguilliformes, Aulopiformes, Perciformes, Scorpaeniformes, Stomiiformes, Synbranchiformes) coincide with six of the seven orders confirmed by Sadovy de Mitcheson and Liu (2008) and seven of the sixteen orders reported by Kuwamura et al. (2020). However, 
for the Cyprinodontiformes, androdioecy rather than hermaphroditism, is the sexual system accepted and this distinction is here taken into account (see below). Two orders containing hermaphrodite species (Centrarchiformes, Gobiiformes) were previously considered as families by Sadovy de Mitcheson and Liu (2008) and two orders (Labriformes and Spariformes) by Kuwamura et al. (2020) are considered families in this study. Thus, there is no net increase in the number of orders in this study with respect to that of Sadovy de Mitcheson and Liu (2008). The presence of hermaphroditism in the order Siluriformes (Avise and Mank 2009) was not included by Sadovy de Mitcheson and Liu (2008) nor in the present study because of lack of direct evidence. The same applies to the orders Cichliformes, Clupeiformes, Cypriniformes, Moroniformes, Tetraodontiformes and Trachiniformes from the study by Kuwamura et al. 2002 .

Overall, the 370 hermaphrodite species identified so far represent $7 \%$ of the total of the 5,268 extant species in the teleost families containing at least one hermaphrodite species, but only $1.1 \%$ of the 33,786 extant species of fish if we include the rest of the families. These figures are in line with previous estimations. Thus, based on information on 25,000 species drawn from FishBase the number of hermaphrodites fish species was estimated $\sim 2 \%$ (Pauly 2004a, b). In their review, Sadovy de Mitcheson and Liu (2008) did not provide a number of hermaphrodite species but estimated that hermaphroditism was present in at least $6 \%$ of teleost families. We find that the percent of hermaphrodite species varies greatly $(<1 \%$ to $100 \%)$ among families but these figures must be taken with caution because of the low number of species for which there is information on sexual system in some families. Of note: regardless of whether one takes into account the five families with the higher number of hermaphrodite species or the families where hermaphroditism is present that contain the higher number $(\geq 100)$ of species, the proportion of hermaphrodite species within a family is at most $24.1 \%$ (Sparidae) but usually much lower.

Recently, Kuwamura et al. (2020) reported a total of 462 hermaphrodite species in fish. Of these, 152 species differ from our database and at least a third $(36 \%)$ show discrepancies with our list for various reasons. First, the evidence used by Kuwamura et al. (2020) was based for some species on the same old bibliographic references lacking direct or functional evidence that led Sadovy de Mitcheson and Liu (2008) and ourselves not to consider those species as hermaphrodites. Some of these species include Rhinomuraena quaesita or several Gonostomatidae species such as Cyclothone atraria, C. microdon, Gonostoma elongatum and Sigmops bathyphilum. Analysis of the gonadal histology or type of gametes present in the gonads did not provide sufficient evidence to confidently classify them as protandric hermaphrodites (Badcock and Merrett 1976; Sshen et al. 1979; Fisher 1983; Miya and Nemoto 1985 1987; Badcock 1986). Regarding the number of families, Kuwamura et al. (2020) report 41 families containing hermaphrodite species, of which seven are different from ours. When checking the sexual systems of the species (1-3 species per family at most) belonging to the families Balistidae, Clupeidae, Cobitidae, Malacanthidae, Moronidae, Poeciliidae and Terapontidae, it was found that the references provided were the same as those used in the Sadovy de Mitcheson and Liu (2008) study, which are proposed but not confirmed as hermaphrodites. Finally, the Creediidae family was not present in the Sadovy de Mitcheson and Liu (2008) paper but, again, there is no reliable evidence (Langston 2004; Shitamitsu and Sunobe 2017). Therefore, this increase in the number of families lacks proper support.

On the other hand, at least a dozen species taken as hermaphrodites in Kuwamura et al. (2020) are confirmed gonochoristic. These species include, for example, some serranids such as Paralabrax maculatofasciatus (Sadovy and Domeier 2005) or epinephelids such as Epinephelus striatus (Sadovy and Colin 1995); sparids such as Diplodus vulgaris (Gonçalves and Erzini 2000), Pagrus major (Matsuyama et al. 1988; Booth and Buxton 1997) or labrids such as Symphodus tinca (Warner and Lejeune 1985) and Bodianus eclancheri (Hoffman 1980). These assignations, coupled with the fact that the total number of species per family used by Kuwamura et al. (2020) was based on Nelson et al. (2016), and that both these numbers and the phylogenetic classification of the teleosts have changed, explains some of the discrepancies in their work. For example, they report $84.2 \%$ of the members of the family Sparidae being hermaphrodites. This number is a gross overestimation because is based on a total number of 38 sparid species, when their actual figure is $\sim 150$ species ( $\mathrm{Pla}$ et al. 2020). Therefore, the study of Kuwamura et al. 
(2020) must be taken with these considerations in mind.

Focusing only on the two major types of hermaphroditism, sequential hermaphroditism $(82.4 \%)$ predominates over simultaneous hermaphroditism $(17.6 \%)$, is in sharp contrast with the situation in plants and invertebrates, where simultaneous hermaphroditism predominates (Leonard 2013). Even if we added the 158 species of simultaneous hermaphrodites of the order Aulopiformes mentioned elsewhere (Baldwin and Johnson 1996; Erisman et al. 2013) but for which we did not find explicit evidence or confirmation, sequential hermaphroditism would still be predominant in fish. The reason for the low numbers of simultaneous hermaphrodites in fish is not known but it could be related to the difficulty of handling sex hormones with opposite functions in the same gonad and with two functional roles at the same time (Warner 1978; Devlin and Nagahama 2002).

Androdioecy, a mixed sexual system where individuals in a population can be simultaneous hermaphrodites or males, but never females, has so far only been described in three species of the genus Kryptolebias ( $K$. ocellatus, $K$. marmoratus and $K$. hermaphroditus) of the Rivulidae family (Costa et al. 2010; Costa 2016). In addition, there are two species of Serranus (S. baldwini and S. psittacinus, the latter often referred to as $S$. fasciatus in previous studies) that have also been considered androdioecious (Erisman et al. 2013). However, unlike Kryptolebias, that in addition to simultaneous hermaphrodites can also contain primary males under certain environmental conditions (Harrington 1971), populations of these serranid species consist of simultaneous hermaphrodites, where a dominant individual will eventually end up losing its female function and behave as a male in a harem of hermaphrodites (Petersen and Fischer 1986; Petersen 1990). Thus, although populations of the species of the genus Kryptolebias and Serranus referred to above can end up consisting of males and simultaneous hermaphrodites, in this study, S. baldwini and $S$. psittacinus were considered simultaneous hermaphrodites, not androdioecious, in line with had been done before by Petersen and Fischer (1986) and Petersen (1990).

Bi-directional sex change is thought to be related to the small size, short life cycle and elevated predation risk (Patzner et al. 2011). Bi-directional sex change has been found naturally in the wild occurring mainly in species of the family Gobiidae (21 species), although instances have been also reported in other families such as Cirrhitidae and Pseudochromidae (Kadota et al. 2012; Kuwamura et al. 2015). However, sometimes evidence has been obtained mainly in laboratory settings after hormonal or social induction as reported, for example, in several species of the family Pomacanthidae (Hioki and Suzuki 1996), Epinephelidae (Tanaka 1990), Labridae (Kuwamura et al. 2002 2007; Ohta et al. 2003) and Pseudochromidae (Wittenrich and Munday 2005; Kuwamura et al. 2015). Many of these bi-directional sex changers (e.g., Cirrhitichthys falco) are mainly protogynous in the wild. Thus, in the present study, only the most common sexual system has been considered in these cases, i.e., protogyny. The species thus concerned have been highlighted in the Supplementary information to denote that they can also be bi-directional under certain circumstances. Adding these species, the incidence of bi-directional sequential hermaphroditism would rise from $7.2 \%$ to $12.7 \%$, a figure similar to that of the number of protandrous species.

\section{Hermaphroditism in freshwater fishes}

Hermaphroditism in freshwater fishes has been traditionally considered to be absent (Wootton and Smith 2014) or rare (Sadovy de Mitcheson and Liu 2008; Pavlov et al. 2009). In our study we attempt to provide the first explicit assessment of the number of hermaphrodite fish species present in freshwater. There are 12 species of hermaphrodites in freshwater (the androdioecious species mentioned above were excluded). These 12 species (3.2\% of all hermaphroditic species) belong to six families (Centropomidae, Gobiidae, Polynemidae, Sparidae, Latidae, and Synbranchidae) representing $\sim 18 \%$ of all families containing hermaphrodites. This might suggest diversity in hermaphroditic freshwater fishes. However, seven of these species belong to families that are typically marine or marine-brackish water (the first four families named above). These species are euryhaline and can live also in freshwater. Thus, there is only five protogynous species that belong to two typically freshwater families: one is the catadromous protandrous Lates calcarifer (Moore 1979; Guiguen et al. 1994), family Latidae, and four protogynous species of the family Synbranchidae: Monopterus boueti, M. albus, Ophisternon bengalense and Synbranchus 
marmoratus (Liem 1963; Liem 1968). However, only $M$. boueti is exclusively freshwater. There are no simultaneous hermaphrodites that exclusively live in freshwater, again if members of the Rivulidae family with androdioecy are not considered. These low numbers do not allow proper correction for phylogenetic signal but given the variety of the families to which the species of hermaphrodites found in freshwater belong it is unlikely that results would be affected.

It has been argued that morphological (e.g., the large eggs typically produced by freshwater fishes, which could accentuate sex-related differences in the anatomy of the reproductive system) and behavioral aspects (e.g., nest building and parental care) could represent a barrier to the development of hermaphrodites (Warner 1978; Sadovy de Mitcheson and Liu 2008). This would be so despite the fact that teleosts have higher potential, compared to other vertebrates, for developing hermaphroditism (Adolfi et al. 2018) due to their gonadal plasticity (Oldfield 2005; Piferrer 2021). In this regard, Lates calcarifer, produces eggs of $0.7-0.8 \mathrm{~mm}$ diameter, i.e., like those of many pelagic marine fishes and in Monopterus boueti, males build a nest and guard the eggs, which does not seem to represent any barrier for the presence of hermaphroditism. Thus, we propose that evolutionary relationships primarily account for the presence or absence of hermaphroditism in freshwater fishes although the influence of morphological or behavioral aspects as mentioned above cannot be ruled out. "Primary" freshwater fish, according to accepted evolutionary classifications (Witten and Huysseune 2009), and exemplified by families such as Cyprinidae and Salmonidae, do not contain hermaphrodite species. All the six families that contain hermaphroditic species that are found in freshwater belong to what can be called the more derived teleosts, where sequential hermaphroditism evolved. Together, these results suggest that hermaphroditism in freshwater species is ultimately influenced by evolutionary history. Comparative studies on the anatomical and physiological aspects that negatively might influence the development of hermaphroditism in freshwater are needed and should examine the families, particularly those comprising species living in different types of salinities, and all the species described in the present study, given their low number. These studies could shed more light on why hermaphroditism is not common in freshwater when compared to marine habitats.

The association of the different sexual systems according to latitude, habitat and depth

Our results confirm the preponderance of sequential hermaphroditism, mainly protogynous hermaphrodites, in rich and complex habitats such as coral reefs. Our permutation tests show that this is not due to the higher number of species present in some latitudes or habitats. Fifteen out of the sixteen families containing protogynous hermaphrodites have species that live in reefs. The exception is the Synbranchidae, one of the two freshwater families with hermaphrodite species. The 45 protogynous species ( $\sim 20 \%$ of all protogynous) not associated with reefs live in demersal and benthopelagic habitats. Although the social system of most of these species is not as well-known as those associated with reefs, the haremic system is present in some (Cole 1983; Kline et al. 2011), suggesting that adaptation to these habitats is possible as long as they maintain their social system, the main driver for protogyny (Warner 1988; Munday et al. 2006).

Regarding latitudinal distribution, protogyny is mainly associated with tropical reefs because of habitat stability and potential for polygamy of adults, among other possible environmental factors (DeMartini and Sikkel 2006) that allows the territoriality and sedentary life required by this system (Warner 1984). However, around 5\% protogynous species have adapted to temperate environments, which are regarded as more unpredictable environments when compared to reefs (DeMartini and Sikkel 2006). But even so, few protogynous species such as Centropyge interruptus and Labrus bergylta inhabit temperate environments and exhibit haremic system (Moyer and Nakazono 1978; Muncaster et al. 2013), again suggesting that adaptation to these latitudes is also possible as long as they maintain their social system. We detected a clear association of protogyny with relatively shallow waters in reef-associated habitat and their absence in bathypelagic and bathydemersal habitats (Fig. 3b).

The distribution of protandrous species, although also most abundant in tropical latitudes $(64 \%$ of species) and in reef habitats, is not as skewed in favor of those habitats as that of protogynous species since they have a similar proportion between reefs and 
demersal habitats ( $\sim 40 \%$ of species in each) with a few species in benthopelagic habitats. In addition, protandrous species have a comparatively more association with brackish water environments as discussed above.

Sequential bi-directional species show, broadly speaking, the same distribution as protogynous species, perhaps even more associated with relatively shallow waters (to $\sim 60 \mathrm{~m}$ depth) and tropical reefs. This tight association may be due to their general small size, short life cycle and elevated risk of predation (Patzner et al. 2011), which does not favor dispersion. In summary, among sequential hermaphrodites, protogynous and bi-directional sex changers have a somehow tighter association with specific habitats when compared to protandrous species, which tend to be more plastic in terms of habitat/distribution requirements. This difference is probably due to the social and mating system characteristic of protogynous species, which normally require complex habitats such as coral reefs that favor the maintenance also of social structure such as harems where a dominant male secures access to a group of females.

Simultaneous hermaphroditism evolved independently in at least four orders (Aulopiformes, Anguilliformes, Gobiiformes, and Perciformes). Thus, it first appeared in basal teleosts, making it the oldest lineage of hermaphrodites (Davis and Fielitz 2010). Simultaneous hermaphroditism, exemplified by members of several families of Aulopiformes, has been associated with the deep-sea (Ghiselin 1969; Baldwin and Johnson 1996; Davis and Fielitz 2010) in accordance with the low-density model (Ghiselin 1969), but simultaneous hermaphrodites of the families Serranidae and Gobiidae inhabit shallower waters. We, therefore, tested the distribution of simultaneous hermaphrodites with depth. We did not consider sequential hermaphrodites because the most abundant type of them, protogyny, are reef-associated, essentially absent or totally absent form bathypelagic or bathydemersal habitats, as our data shows (Fig. 3b). The absence in certain depth categories made us consider that there was no need to test depth with sequential hermaphroditism.

Our analysis showed a similar number of simultaneous hermaphrodites in shallow $(\leq 200 \mathrm{~m})$ waters and depths $>400 \mathrm{~m}$ (ratio 1:1.2). Even assuming that all of the 126 species of Aulopiformes mentioned in Baldwin and Johnson (1996) for which we could not confirm their sexual system lived exclusively in deep waters, the distribution of simultaneous hermaphroditism in fish is not only associated with the deep sea. In fish, simultaneous hermaphroditism has a significant probability of being found in both reefs and bathypelagic habitats, in the latter being more likely than other sexual systems. Thus, while it is true that simultaneous hermaphroditism is the only type of hermaphroditism present in the deep sea, the opposite is not true, i.e., simultaneous hermaphrodites live both in the deep sea and in shallow waters in roughly similar proportions based on the number of confirmed species at present.

In summary, we have provided the first attempt to quantify, utilizing only species which are confirmed hermaphrodites, the incidence and distribution of the different forms of hermaphroditism in fish focusing on the influence on abiotic factors, an area underexplored when compared to the influence of the social environment mating behavior and spawning mode. Of note, our data lacks control for phylogenetic signal, which could introduce some bias in the analysis of the role of environmental correlates we show. We could not correct for phylogeny due to the limited number of species present in some forms of hermaphroditism. However, close inspection of the data where in principle correction for phylogeny could potentially be useful, e.g., data presented in Fig. 4a indicates an even distribution of species among different depths, suggesting that correcting for phylogenetic signal would not significantly alter the results. The randomization tests showed that the associations we found between the different sexual systems and latitude, habitat and depth are indeed real and not influenced by the higher abundance of species in some latitudes, habitats or depths. This however, does not diminish the importance of biotic factors in explaining the distribution of hermaphroditism. In fact, both biotic and abiotic factors must act together for making the presence of hermaphroditism possible.

To conclude, the major insights that our study bring to the knowledge of hermaphroditism in fishes can be summarized as follows: 1) we have attempted, for the first time, to quantify at the species level the phylogenetic distribution of hermaphroditism in fish, considering only species in which it has been confirmed, 2) we show the higher presence of the most abundant form of hermaphroditism in some latitudes and habitats is not merely due to the fact that these 
habitats are the most rich in species abundance, 3) the scarce presence of hermaphroditism in freshwater fishes seems better explained by evolutionary relationships rather than by morphological or anatomical constraints, although these cannot be excluded, and 4) simultaneous hermaphroditism appears as common in shallow waters and complex environments as it is in deep-water ecosystems with very low encounter probabilities. This study can serve as the basis for further research in specific groups for different purposes, including ecological and evolutionary studies. Theories that account for environmental heterogeneity predicts that biotic interactions determine distribution limits under benign climatic conditions while abiotic limitations set distribution limits under harsh climatic conditions (Gaston 2009; Louthan et al. 2015). Therefore, our study can also be useful to better understand possible distribution shifts in response to global change, mainly due to increases in temperatures that could affect the reproductive dynamics of hermaphrodites and dispersion of larvae, hence risking mismatches with other environmental factors. This is particularly relevant taking into account that many hermaphrodite fish species sustain important fisheries.

Acknowledgements Research supported by MEC grant AGL2013-41047-R to FP. SP was supported by AGL201341047-R contracts. We thank Dr. Domingo Lloris, Sergi Messeguer and Dr. Natalia Ospina-Álvarez for providing information and contributing to an early, uncured version of the database. Thanks also to David Marcuello for providing access to the FishBase server. We also acknowledge the funding of the Spanish government through the 'Severo Ochoa Centre of Excellence' accreditation (CEX2019-000928-S) and grant PID2019-108888RB-I00.

Author contributions FP conceived the study; FP and SP designed the study; SP collected the data; SP and FM analyzed the data; SP and FP wrote the manuscript. All authors revised and approved the manuscript.

Funding Open Access funding provided thanks to the CRUECSIC agreement with Springer Nature.

Open Access This article is licensed under a Creative Commons Attribution 4.0 International License, which permits use, sharing, adaptation, distribution and reproduction in any medium or format, as long as you give appropriate credit to the original author(s) and the source, provide a link to the Creative Commons licence, and indicate if changes were made. The images or other third party material in this article are included in the article's Creative Commons licence, unless indicated otherwise in a credit line to the material. If material is not included in the article's Creative Commons licence and your intended use is not permitted by statutory regulation or exceeds the permitted use, you will need to obtain permission directly from the copyright holder. To view a copy of this licence, visit http://creativecommons.org/licenses/by/4.0/.

Data availability statement All the data used in the present study is contained in the online Supplementary information.

\section{References}

Adolfi MC, Nakajima RT, Nóbrega RH, Schartl M (2018) Intersex, hermaphroditism, and gonadal plasticity in vertebrates: Evolution of the müllerian duct and amh/amhr2 signaling. Ann Rev Animal Biosci. https://doi.org/10. 1146/annurev-animal-020518-114955

Atz JW (1964) Intersexuality in fishes. In: Armstrong CN, Marshall AJ (eds) Intersexuality in vertebrates including man. Academic Press, London, pp 145-232

Avise JC, Mank JE (2009) Evolutionary perspectives on hermaphroditism in fishes. Sex Dev 3(2-3):152-163. https:// doi.org/10.1159/000223079

Bachtrog D, Mank JE, Peichel CL, Kirkpatrick M, Otto SP, Ashman T-L, Ming R (2014) Sex determination: why so many ways of doing it? PLoS Biol 12(7):e1001899. https:// doi.org/10.1371/journal.pbio.1001899

Badcock J (1986) Aspects of the reproductive biology of Gonostoma bathyphilum (Gonostomatidae). J Fish Biol 29(5):589-603. https://doi.org/10.1111/j.1095-8649.1986. tb04975.x

Badcock J, Merrett NR (1976) Midwater fishes in the eastern North Atlantic-I. Vertical distribution and associated biology in $30 \mathrm{~N}, 23 \mathrm{~W}$, with developmental notes on certain myctophids. Prog Ocean 7(1):3-58. https://doi.org/10. 1016/0079-6611(76)90003-3

Baldwin CC, Johnson GD (1996) Interrelationships of aulopiformes. In: Stiassny MLJ, Parenti LR, Johnson GD (eds) Interrelationships of fishes. Academic Press, San Diego, pp 355-404

Barlow GW (1975) On the sociobiology of some hermaphroditic serranid fishes, the hamlets, in Puerto Rico. Mar Biol 33:295-300. https://doi.org/10.1007/BF00390567

Blomberg SP, Garland T Jr (2002) Tempo and mode of evolution: phylogenetic inertia, adaption and comparative methods. J Evol Biol 15:899-2010

Booth AJ, Buxton CD (1997) The biology of the panga, Pterogymnus laniarius (Teleostei: Sparidae), on the Agulhas Bank South Africa. Environ Biol Fish 49(2):207-226. https://doi.org/10.1023/A:1007362700687

Butler EC, Childs A-R, Winkler AC, Milner MV, Potts WM (2018) Evidence for protandry in Polydactylus quadrifilis in the Kwanza Estuary, Angola, and its implications for local fisheries. Environ Biol Fishes 101(2):301-313. https://doi.org/10.1007/s10641-017-0699-6

Carruth LL (2000) Freshwater cichlid Crenicara punctulata is a protogynous sequential hermaphrodite. Copeia 1:71-82. https://doi.org/10.1643/0045-8511(2000)2000[0071: FCCPIA]2.0.CO;2 
Charnov EL (1979) Simultaneous hermaphroditism and sexual selection. Proc Natl Acad Sci 76(5):2480-2484. https://doi. org/10.1073/pnas.76.5.2480

Charnov EL (1982) The theory of sex allocation. Princeton University Press, New Yersey

Cole KS (1983) Protogynous hermaphroditism in a temperate zone territorial marine goby. Coryphopterus nicholsi Copeia 3:809-812

Cole KS (2010) Gonad morphology in hermaphroditic gobies. In: Cole KS (ed) Reproduction and sexuality in marine fishes: patterns and processes. University of California Press, Berkeley, CA, pp 117-164

Collares-Pereira M, Matos I, Morgado-Santos M, Coelho M (2013) Natural pathways towards polyploidy in animals: the Squalius alburnoides fish complex as a model system to study genome size and genome reorganization in polyploids. Cytogenet Genome Res 140(2-4):97-116. https:// doi.org/10.1159/000351729

Conover D (1992) Seasonality and the scheduling of life history at different latitudes. J Fish Biol 41:161-178. https://doi. org/10.1111/j.1095-8649.1992.tb03876.x

Costa W (2016) Colouration, taxonomy and geographical distribution of mangrove killifishes, the Kryptolebias marmoratus species group, in southern Atlantic coastal plains of Brazil (Cyprinodontiformes: Rivulidae). Ichthyol Explor Freshwaters 27(2):183-192

Costa WJ, Lima SM, Bartolette R (2010) Androdioecy in Kryptolebias killifish and the evolution of self-fertilizing hermaphroditism. Biol J Lin Soc 99(2):344-349. https:// doi.org/10.1111/j.1095-8312.2009.01359.x

Davis MP, Fielitz C (2010) Estimating divergence times of lizardfishes and their allies (Euteleostei: Aulopiformes) and the timing of deep-sea adaptations. Mol Phylogenet Evol 57(3):1194-1208. https://doi.org/10.1016/j.ympev. 2010.09.003

DeMartini EE, Sikkel PC (2006) Reproduction. In: Allen LG, Pondella DJ, Horn MH (eds) The Ecology of Marine Fishes - California and Adjacent Waters. University of California Press, San Francisco, pp 483-523

Devlin RH, Nagahama Y (2002) Sex determination and sex differentiation in fish: an overview of genetic, physiological, and environmental influences. Aquaculture 208(3-4):191-364. https://doi.org/10.1016/S00448486(02)00057-1

Eppley S, Jesson L (2008) Moving to mate: the evolution of separate and combined sexes in multicellular organisms. J Evol Biol 21(3):727-736. https://doi.org/10.1111/j.14209101.2008.01524.x

Erisman BE, Hastings PA (2011) Evolutionary transitions in the sexual patterns of fishes: Insights from a phylogenetic analysis of the seabasses (Teleostei: Serranidae. Copeia 3:357-364. https://doi.org/10.1643/CG-10-086

Erisman BE, Petersen CW, Hastings PA, Warner RR (2013) Phylogenetic perspectives on the evolution of functional hermaphroditism in teleost fishes. Integr Comp Biol 53(4):736-754. https://doi.org/10.1093/icb/ict077

Fisher RA (1983) Protrandric sex reversal in Gonostoma elongatum (Pisces: Gonostomatidae) from the Eastern Gulf of Mexico. Copeia 2:554-557. https://doi.org/10.2307/ 1444411
Freedman JA, Noakes DL (2002) Why are there no really big bony fishes? A point-of-view on maximum body size in teleosts and elasmobranchs. Rev Fish Biol Fisheries 12(4):403-416. https://doi.org/10.1023/A:1025365210414

Fricke R, Eschmeyer WNR, van der Laan (eds) (2019) Eschmeyer's catalog of fishes: genera, species. http:// researcharchive.calacademy.org/research/ichthyology/ catalog/fishcatmain.asp). Electronic version. Accessed Feb 2019

Froese R, Pauly D (eds) (2018) FishBase. World wide web electronic publication. http://www.fishbase.org. Electronic version. Accessed June 2018

Gaston KJ (2009) Geographic range limits: achieving synthesis. In: Proceedings of the Royal Society B, vol 276, pp 1395-1406

Ghiselin MT (1969) The evolution of hermaphroditism among animals. Q Rev Biol 44(2):189-208. https://doi.org/10. $1086 / 406066$

Godwin J (2009) Social determination of sex in reef fishes. Semin Cell Dev Biol 20:264-270

Gonçalves J, Erzini K (2000) The reproductive biology of the two-banded sea bream (Diplodus vulgaris) from the southwest coast of Portugal. J Appl Ichthyol 16(3):110-116. https://doi.org/10.1046/j.1439-0426.2000. 00232.x

Guiguen Y, Cauty C, Fostier A, Fuchs J, Jalabert B (1994) Reproductive cycle and sex inversion of the seabass, Lates calcarifer, reared in sea cages in French Polynesia: histological and morphometric description. Environ Biol Fishes 39(3):231-247. https://doi.org/10.1007/BF00005126

Harrington RW (1971) How ecological and genetic factors interact to determine when self-fertilizing hermaphrodites of Rivulus marmoratus change into functional secondary males with a reappraisal of the modes of intersexuality among fishes. Copeia 1971(3):389-432. https://doi.org/10. 2307/1442438

Heibo E, Magnhagen C, Vøllestad LA (2005) Latitudinal variation in life-history traits in Eurasian perch. Ecology 86(12):3377-3386. https://doi.org/10.1890/04-1620

Hioki S, Suzuki K (1996) Sex changing from male to female on the way of protogynous process in three Centropyge angelfishes (Pomacanthidae: Teleostei). Bull Ins Oceanic Research Develop Tokai Univ 17:27-34

Hoffman SG (1980) Sex-related social, mating and foraging behavior in some sequentially hermaphroditic reef fishes. Unpublished PhD dissertation, University of California, Santa Barbara, CA

Jarne P, Auld JR (2006) Animals mix it up too: the distribution of self-fertilization among hermaphroditic animals. Evolution 60(9):1816-1824. https://doi.org/10.1111/j.00143820.2006.tb00525.x

Kadota T, Osato J, Nagata K, Sakai Y (2012) Reversed sex change in the haremic protogynous hawkfish Cirrhitichthys falco in natural conditions. Ethology 118(3):226-234

Kline RJ, Khan IA, Holt GJ (2011) Behavior, color change and time for sexual inversion in the protogynous grouper (Epinephelus adscensionis). PLoS One 6(5):e19576

Kuwamura T, Tanaka N, Nakashima Y, Karino K, Sakai Y (2002) Reversed sex-change in the protogynous reef fish Labroides dimidiatus. Ethology 108(5):443-450. https:// doi.org/10.1046/j.1439-0310.2002.00791.x 
Kuwamura T, Suzuki S, Tanaka N, Ouchi E, Karino K, Nakashima Y (2007) Sex change of primary males in a diandric labrid Halichoeres trimaculatus: coexistence of protandry and protogyny within a species. J Fish Biol 70(6):1898-1906. https://doi.org/10.1111/j.1095-8649. 2007.01464.x

Kuwamura T, Kadota T, Suzuki S (2015) Bidirectional sex change in the magenta dottyback Pictichromis porphyrea: first evidence from the field in Pseudochromidae. Environ Biol Fish 98(1):201-207

Kuwamura T, Sunobe T, Sakai Y, Kadota T, Sawada K (2020) Hermaphroditism in fishes: an annotated list of species, phylogeny, and mating system. Ichthyol Res. https://doi. org/10.1007/s10228-020-00754-6

Langston RC (2004) Gonad morphology and sex change in sandburrowers (Teleostei: Creediidae). $\mathrm{PhD}$ dissertation. University of Hawaii, Manoa, 138 pp

Leonard JL (1990) The hermaphrodite's dilemma. J Theor Biol 147(3):361-371. 5193(05)80493-X https://doi.org/10.1016/S0022-

Leonard JL (2010) The evolution of sexes, anisogamy and sexual systems. In: Leonard J, Córdoba-Aguilar A (eds) The evolution of primary sexual characters in animals. Oxford University Press, New York, pp 15-39

Leonard JL (2013) Williams' paradox and the role of phenotypic plasticity in sexual systems. Integr Comp Biol 53(4):671-688. https://doi.org/10.1093/icb/ict088

Leonard JL (2018) Transitions between sexual systems: understanding the mechanisms of, and pathways between, dioecy, hermaphroditism and other sexual systems, 1st edn. Springer, New York, NY. https://doi.org/10.1007/978-3319-94139-4

Lewis D (1942) The evolution of sex in flowering plants. Biol Rev 17(1):46-67. https://doi.org/10.1111/j.1469-185X. 1942.tb00431.x

Liem KF (1963) Sex reversal as a natural process in the Synbranchiform fish Monopterus albus. Copeia 1963(2):303-312. https://doi.org/10.2307/1441348

Liem KF (1968) Geographical and taxonomic variation in the pattern of natural sex reversal in the teleost fish order Synbranchiformes. J Zool 156(2):225-238. https://doi.org/ 10.1111/j.1469-7998.1968.tb05930.x

Louthan AM, Doak DF, Angert AL (2015) Where and when do species interactions set range limits? Trends in Ecology Evolution 30:780-792

Manabe H, Toyoda K, Nagamoto K, Dewa S-I, Sakurai M, Hagiwara K, Sunobe T (2013) Bidirectional sex change in seven species of Priolepis (Actinopterygii: Gobiidae). Bull Mar Sci 89(2):635-642. https://doi.org/10.5343/bms.2012. 1050

Mank JE, Promislow DE, Avise JC (2006) Evolution of alternative sex-determining mechanisms in teleost fishes. Biol J Lin Soc 87(1):83-93. https://doi.org/10.1111/j.1095-8312. 2006.00558.x

Margalef R (1998) Ecología, 9th edn. Ediciones Omega, Barcelona

Matos I, Machado M, Sucena E, Collares-Pereira M, Schartl M, Coelho M (2010) Evidence for hermaphroditism in the Squalius alburnoides allopolyploid fish complex. Sexual Develop 4(3):170-175. https://doi.org/10.1159/000313359
Matsuyama M, Lara RT, Matsuura S (1988) Juvenile bisexuality in the red sea bream, Pagrus major. Environ Biol Fishes 21(1):27-36. https://doi.org/10.1007/BF02984440

Menke SB, Holway DA (2006) Abiotic factors control invasion by Argentine ants at a community scale. J Animal Ecol 75:368-376. https://www.jstor.org/stable/3505581

Miya M, Nemoto T (1985) Protandrous sex reversal in $C y$ clothone atraria (family Gonostomatidae). Japanese J Ichthyol 31(4):438-440. https://doi.org/10.11369/jji1950. 31.438

Miya M, Nemoto T (1987) Reproduction, growth and vertical distribution of the meso-and bathypelagic fish Cyclothone atraria (Pisces: Gonostomatidae) in Sagami Bay, Central Japan. Deep Sea Res Part A: Ocean Res Papers 34(9):1565-1577. https://doi.org/10.1016/01980149(87)90109-9

Moore R (1979) Natural sex inversion in the Giant Perch (Lates calcarifer). Mar Freshw Res 30(6):803-813. https://doi. org/10.1071/MF9790803

Moyer JT, Nakazono A (1978) Protandrous hermaphroditism in six species of the anemonefish genus Amphiprion in Japan. Japan J Ichthyol 25(2):101-106

Muncaster S, Andersson E, Kjesbu OS, Taranger GL, Skiftesvik AB, Norberg B (2010) The reproductive cycle of female Ballan wrasse Labrus bergylta in high latitude, temperate waters. J Fish Biol 77(3):494-511. https://doi.org/10.1111/ j.1095-8649.2010.02691.x

Muncaster S, Norberg B, Andersson E (2013) Natural sex change in the temperate protogynous Ballan wrasse Labrus bergylta. J Fish Biol 82(6):1858-1870. https://doi.org/10. 1111/jfb. 12113

Munday PL, Buston PM, Warner RR (2006) Diversity and flexibility of sex-change strategies in animals. Trendss Ecol Evolut 21(2):89-95. https://doi.org/10.1016/j.tree. 2005.10.020

Munday PL, Kuwamura T, Kroon FJ (2010) Bidirectional sex change in marine fishes. In: Cole KS (ed) Reproduction and sexuality in marine fishes: patterns and processes. University of California Press, Berkeley, California, pp 241-271. https://doi.org/10.1525/9780520947979-011

Nelson JS, Grande TC, Wilson MV (2016) Fishes of the World, 5 th edn. John Wiley Sons, Hoboken, NJ

Ohta K, Sundaray J, Okida T, Sakai M, Kitano T, Yamaguchi A, Matsuyama M (2003) Bi-directional sex change and its steroidogenesis in the wrasse Pseudolabrus sieboldi. Fish Physiol Biochem 28(1-4):173-174. https://doi.org/10. 1023/B:FISH.0000030517.06738.e7

Oldfield RG (2005) Genetic, abiotic and social influences on sex differentiation in cichlid fishes and the evolution of sequential hermaphroditism. Fish Fish 6(2):93-110. https://doi.org/10.1111/j.1467-2979.2005.00184.x

Orzack SH, Sober E (2001) Adaptation, phylogenetic inertia, and the method of controlled comparisons. In: Orzack SH, Sober E (eds) Adaptationism and Optimality. Cambridge University Press, Cambridge, pp 45-63

Pankhurst NW, Munday PL (2011) Effects of climate change on fish reproduction and early life history stages. Mar Freshw Res 62:1015-1026

Patzner R, Van Tassell JL, Kovacic M, Kapoor B (2011) The biology of gobies. In: Herler J, Munday PL, Hernaman V 
(eds) Gobies on coral reefs. Science Publishers, St.Helier, pp 493-529

Pauly D (2004a) Darwin's fishes: An encyclopedia of ichthyology, ecology, and evolution. Cambridge University Press, Cambridge

Pauly D (2004b) FishBase 2000 - FishBase concept, design and data sources (FishBase 2000 users manual)

Pavlov DA, Emel'yanova NG, Novikov GG (2009) Reproductive dynamics. In: Jakobsen T, Fogarty MJ, Megrey BA, Moksness E (eds) Fish reproductive biology. WileyBlackwell Scientific Publications, Oxford, UK, pp 48-69. https://doi.org/10.1002/9781118752739.ch2

Petersen CW (1990) The relationships among population density, individual size, mating tactics, and reproductive success in a hermaphroditic fish Serranus fasciatus. Behaviour 113(1-2):57-80. https://doi.org/10.1163/ $156853990 X 00437$

Petersen CW, Fischer EA (1986) Mating system of the hermaphroditic coral-reef fish, Serranus baldwini. Behav Ecol Sociobiol 19(3):171-178. https://doi.org/10.1007/ BF00300857

Piferrer F (2021) Epigenetic mechanisms in sex determination and in the evolutionary transitions between sexual systems. Phil Trans R Soc B 376:20200110. https://doi.org/10.1098/ rstb.2020.0110

Pla S (2019) Evolutionary transitions, environmental correlates and life-history traits associated with the distribution of the different forms of hermaphroditism in fish. $\mathrm{PhD}$. thesis. Universitat Autònoma de Barcelona, Spain, 215 pp.

Pla S, Benvenuto C, Capellini I, Piferrer F (2020) A phylogenetic comparative analysis on the evolution of sequential hermaphroditism in seabreams (Teleostei: Sparidae). Sci Rep 10(1):1-12. https://doi.org/10.1038/s41598-02060376-w

Rabosky DL, Chang J, Title PO, Cowman PF, Sallan L, Friedman M, Coll M (2018) An inverse latitudinal gradient in speciation rate for marine fishes. Nature 559(7714):392-395. https://doi.org/10.1038/s41586-0180273-1

Ripley B, Venables W, Ripley MB (2016) Package 'nnet.' R Package Version 7:3-12

Ruttenberg BI, Haupt AJ, Chiriboga AI, Warner RR (2005) Patterns, causes and consequences of regional variation in the ecology and life history of a reef fish. Oecologia 145:394-403

Sadovy Y, Shapiro DY (1987) Criteria for the diagnosis of hermaphroditism in fishes. Copeia 1:136-156. https://doi. org/10.2307/1446046

Sadovy Y, Colin P (1995) Sexual development and sexuality in the Nassau grouper. J Fish Biol 46(6):961-976. https://doi. org/10.1111/j.1095-8649.1995.tb01401.x

Sadovy Y, Domeier ML (2005) Perplexing problems of sexual patterns in the fish genus Paralabrax (Serranidae, Serraninae). J Zool 267(2):121-133. https://doi.org/10.1017/ S0952836905007466

Sadovy de Mitcheson Y, Liu M (2008) Functional hermaphroditism in teleosts. Fish Fish 9(1):1-43. https://doi.org/10. 1111/j.1467-2979.2007.00266.x

Sallan L, Friedman M, Sansom RS, Bird CM, Sansom IJ (2018) The nearshore cradle of early vertebrate diversification.
Science 362(6413):460-464. https://doi.org/10.1126/ science.aar3689

Shihab I, Gopalakrishnan A, Vineesh N, Muktha M, Akhilesh K, Vijayagopal P (2017) Histological profiling of gonads depicting protandrous hermaphroditism in E leutheronema tetradactylum. J Fish Biol 90(6):2402-2411. https://doi. org/10.1111/jfb.13324

Shitamitsu T, Sunobe T (2017) Notes on protandry in the creediid fishes Limnichthys fasciatus and L nitidus (Teleostei: Creediidae). Ichthyol Research 64(3):365-367

Sshen S, Lin J, Liu C (1979) Redescription of a protandrous hermaphroditic moray eel (Rhinomuaena quaesita Garman). Bull Inst Zool Acad Sinica 18(2):79-87

Sunobe T, Nakazono A (1993) Sex change in both directions by alteration of social dominance in Trimma okinawae (Pisces: Gobiidae). Ethology 94(4):339-345. https://doi.org/ 10.1111/j.1439-0310.1993.tb00450.x

Sunobe T, Sado T, Hagiwara K, Manabe H, Suzuki T, Kobayashi Y, Miya M (2017) Evolution of bidirectional sex change and gonochorism in fishes of the gobiid genera Trimma, Priolepis, and Trimmatom. Sci Nat 104(3-4):15. https://doi.org/10.1007/s00114-017-1434-z

Tanaka H (1990) Sexual maturation and sex reversal in red spotted grouper, Epinephelus akaara. Bull Natl Res Inst Aquacult 17:1-15

Tomlinson J (1966) The advantages of hermaphroditism and parthenogenesis. J Theor Biol 11(1):54-58. https://doi.org/ 10.1016/0022-5193(66)90038-5

Trip EL, Choat JH, Wilson DT, Robertson DR (2008) Interoceanic analysis of demographic variation in a widely distributed Indo-Pacific coral reef fish. Mar Ecol Prog Ser 373:97-109. https://doi.org/10.3354/meps07755

Trip EDL, Raubenheimer D, Clements KD, Choat JH (2011) Reproductive demography of a temperate protogynous and herbivorous fish, Odax pullus (Labridae, Odacini). Mar Freshw Res 62(2):176-186. https://doi.org/10.1071/ MF10238

Vega GC, Wiens JJ (2012) Why are there so few fish in the sea? Proc Royal Soc B: Biol Sci 279(1737):2323-2329. https:// doi.org/10.1098/rspb.2012.0075

Warner RR (1975) The adaptive significance of sequential hermaphroditism in animals. Am Nat 109(965):61-82. https://doi.org/10.1086/282974

Warner RR (1978) The evolution of hermaphroditism and unisexuality in aquatic and terrestrial vertebrates. In: Reese ES, Lighter FJ (eds) Contrasts in behavior adaptations in the aquatic and terrestrial environments. Wiley Sons, Toronto

Warner RR (1982) Mating systems, sex change and sexual demography in the rainbow wrasse Thalassoma lucasanum. Copeia 3:653-661. https://doi.org/10.2307/1444666

Warner RR (1984) Mating behavior and hermaphroditism in coral reef fishes. Am Sci 72:128-136

Warner RR (1988) Sex change and the size-advantage model. Trends Ecol Evolut 3(6):133-136. https://doi.org/10.1016/ 0169-5347(88)90176-0

Warner RR, Lejeune P (1985) Sex change limited by paternal care: a test using four Mediterranean labrid fishes, genus Symphodus. Mar Biol 87(1):89-99. https://doi.org/10. 1007/BF00397010 
Williams GC (1975) Sex and evolution. Princeton University Press, Princeton

Witten PE, Huysseune A (2009) A comparative view on mechanisms and functions of skeletal remodelling in teleost fish, with special emphasis on osteoclasts and their function. Biol Rev 84(2):315-346. https://doi.org/10.1111/ j.1469-185X.2009.00077.x

Wittenrich ML, Munday PL (2005) Bi-directional sex change in coral reef fishes from the family Pseudochromidae: an experimental evaluation. Zoolog Sci 22(7):797-804. https://doi.org/10.2108/zsj.22.797
Wootton RJ, Smith C (2014) Reproductive biology of teleost fishes, 1st edn. Wiley-Blackwell, Oxford

Yamamoto TO (1969) Sex differentiation. In: Hoar WS, Randall DJ (eds) Fish physiology III. Academic Press, New York, pp 117-175. https://doi.org/10.1016/S15465098(08)60113-2

Publisher's Note Springer Nature remains neutral with regard to jurisdictional claims in published maps and institutional affiliations. 